\title{
Personality Trait and Attitude towards Domestic Violence among Currently Married Women in South- West Nigeria
}

\author{
Motunrayo Idiat FASASI \\ Health Centre Services, Obafemi Awolowo University, Ile-Ife, Nigeria
}

\begin{abstract}
Background: In Nigeria, the prevalence of domestic violence (spousal) among women age 15-49 years indicate an upward trend, from $25 \%$ in 2008 to $31 \%$ in 2013 and $36 \%$ in 2018. However, data also indicates more than one quarter of women in Nigeria as at 2018 support wife beating under certain circumstances. Despite studies linking personality trait to attitude towards violence, studies in this regard seems to receive little or no attention in Nigeria. This study, examines the effect of personality trait on attitude of women towards domestic violence in Nigeria.
\end{abstract}

Methods: The study collected primary data, while adopting a cross-sectional research design. The study population comprised of women of reproductive age (15-49) years, currently married, and living with their partner. A total of 400 women who had experienced domestic violence were purposively surveyed to represent the southwest region. Hierarchical Multiple Regression analysis was performed. Data for the study was analyzed using SPSS Version 22 software.

Results: Findings from the study showed high prevalence of verbal/emotional violence $(60 \%)$, followed by physical violence (37\%) and sexual violence (23\%). Also, $47 \%$ of the women demonstrated a negative (supportive) attitude towards domestic violence. The multivariate result revealed of the five personality type (Big Five) examined, three namely: agreeableness, conscientiousness and neuroticism significantly predicted attitude towards domestic violence.

Conclusion: The study found nearly half of the women demonstrated supportive attitude towards domestic violence, while personality trait was an important predictor of attitude towards domestic violence.

Keywords: Personality trait, domestic violence, attitude, currently married

\section{INTRODUCTION}

$\mathrm{W}$ orldwide, $35 \%$ of women are reported to experience Domestic Violence (DV) in their life time [1]. In Nigeria, the prevalence of domestic violence (spousal) among women age 15-49 years continues to increase, from $25 \%$ in 2008 to $31 \%$ in 2013 and $36 \%$ in 2018. Also, women in Nigeria continue to exhibit attitude that condone violence from their partner on certain grounds, with more than one quarter of women in Nigeria supporting wife beating under certain circumstances [2]. According to the most recent Nigeria Demographic and Health Survey 2018, 28\% of women support wife beating by the man if she engages in at least one of the following act: argues with her husband, burns food, goes out without informing her partner, neglects the children and refuses to have sexual intercourse with her partner. Surprisingly, the prevalence rate for support of wife beating was even lower among the men $(21 \%)$. Although the prevalence rate for support of wife beating has been declining over the years from $45 \%$ in 2008, 35\% in 2013 and $28 \%$ in 2018 [2].

Domestic Violence refers to any behaviour by an intimate partner or ex-partner that can cause physical, sexual or psychological in addition to physical violence, coercion sexually, psychological abuse and controlling behaviour [3]. In this study, domestic violence is also defined as the exposure of woman to all or any of physical, sexual or emotional violence from their male partner. Attitude on the other hand, has been defined as the way through which an individual evaluates or appraises something as a result of individual's beliefs, feelings and intended behaviour [4]. Attitude toward violence has to do with the willingness of an individual in an intimate relationship to tolerate or not tolerate certain behaviour that might be considered abusive or violent by their partner.

Attitude is considered germane when explaining violence against women. Attitude has been linked to the perpetration of violence, response of the victim to the act and the response of the community [5]. In most settings, especially in a more conservative society, women have been found to endorse perpetration of violence from their partner, while their attitude also determined how the society react to such acts of violence [6]. With respect to wife beating, data from a multi country study [7] revealed a wide variation in proportion of women who supported wife beating. The rate was $90 \%$ in Jordan, Ethiopia (81\%), Somalia (76.5\%), Mali (75\%), Vietnam $(63.8 \%)$, India $(54.4 \%)$ and Iraq $(59.1 \%)$, representing countries with higher prevalence rate of support for wife beating among the women. On the other hand, countries with low prevalence rate in terms of support for wife beating include: Nepal (23.2\%), Kazakhstan (10.4\%), Georgia (6.9\%) and Serbia $(6.2 \%)$. The above data implies support for wife beating was generally higher among women from Africa and Asia. There is no doubt that factors such as cultural, religious and socio-economic status among others could have influenced this differential. For instance, a study [6] which 
investigated community and social factors associated with attitude of women towards domestic violence found significant association between beliefs that support violence and the perpetration of violent behaviour at individual and community level.

Notwithstanding, several factors can influence the attitude of women towards domestic violence. These factors include individual factors (such as age, education, wealth status, autonomy among others) and community belief and endorsement of violence against women and religion among others [8], [9], [10], [11], personal factors namely: personality trait (an example is the Big Five Personality Inventory which consists of agreeableness, conscientiousness, neuroticism, extraversion and openness) and self-esteem, which refers to how an individual rate themselves and self-worth [12], [13]. Personality refers to sets of expected behaviour, perception and emotional patterns that originate from biological and environmental factors [14]. While studies above have linked individual, socio-cultural/religious factors with attitude and perpetration of violence against women, not much research has been done to link personality type to attitude towards domestic violence, especially in Nigeria, despite the upward trend in perpetuation of violence against women.

Studies [15], [16], [17], [18] have found personality trait such as neuroticism and agreeableness to be strong predictors of attitude towards violence. Neuroticism for instance, has been associated with hostility and impatience, which makes individuals with such personality trait to be aggressive and reactive [19]. People with agreeableness personality on the other hand, are considered tolerant and supportive and nonviolent in relationships [20]. Therefore, understanding how personality trait shapes attitude towards domestic violence will help in uncovering salient factors and also assist in developing appropriate strategy and interventions that seek to reduce/eliminate violence against women.

In spite of the importance of attitude in shaping perpetration and acceptance of domestic violence against women, not much has been done to ascertain the connection between personality traits and attitude that condone the perpetration of violence against women, thereby making women more vulnerable to domestic violence. A good understanding of factors that shapes attitude of women towards domestic violence will provide relevant input into policies seeking to reduce the prevalence of violence against women [21]. Hence, this study examines the effect of personality trait on attitude towards domestic violence among women in Southwest Nigeria.

\section{METHODS AND MATERIALS}

\section{Study Population, Sampling and Sample Size}

The study adopted a mix method approach, involving the collection of quantitative and qualitative data. Quantitative data was collected using cross-sectional survey research design. However, the report presented in this paper is restricted to the quantitative data collected. The sample for the study was drawn from three out of the six states in South-west Nigeria namely: Ogun, Ondo and Oyo states. The rationale for selecting the three states was based on the fact that the three states can effectively represents the entire region due to their homogenous nature both in cultural, educational and socioeconomic attributes. The states have also been reported to have one of the highest prevalence in domestic violence in the region by previous demographic and health surveys [2]. The study population consist of women of reproductive age (15-49 years), currently married and living with their partner. A sample of 400 women were selected and surveyed from the three states using proportional sampling to ensure full representation according to states. The sample frame was based on the reported total population for each of the LGAs chosen in each state, as reported by the 2006 National Population Census and projected to 2016.

\section{Data Collection/Instrument}

Data for the study was collected using a structured questionnaire. The original instrument was prepared in English Language. However, it was translated and backtranslated to local languages to ensure the original meaning was retained, while effort was also made to translate it into the local language for those who were not learned and semiilliterates. Before embarking on field administration, a pilot study was conducted among 50 women located outside the study area to ascertain the validity and reliability of the questionnaire. The reliability analysis using the Cronbach alpha test yielded a reliability value of $\alpha=0.876$, which was considered adequate, implying the instrument was reliable and measured what was expected. The final instrument was validated by two experts from the Department of Psychology. Experience of domestic violence was measured using series of questions that measures physical, verbal/emotional and sexual violence. The questions for experience of any of the violence was dichotomized yes $=1$ or no $=0$, while prevalence of any of the violence was measured as often, occasional, never and more than 12 months preceding the survey.

\section{Measurement of Outcome Variable}

The outcome variable for this study is attitude towards domestic violence. Attitude was measured on a four point Likert scale such as strongly agree $=4$, agree $=3$, disagree $=2$ and strongly disagree $=1$. Attitude towards domestic violence was assessed using a self-developed scale by the researcher which asked series of questions including: perpetrator of sexual violence should always be reported for prosecution; there is nothing wrong if a woman who has cheated on her husband is physically abused by her partner; a married woman who refused her partner sexual demand cannot complain if she is sexually abused by her partner; women can sometimes be adamant and stubborn, therefore, their partners cannot be blamed if they physically or sexually abuse them and men will always be men, so, women need not to report domestic violence against them to the appropriate authority among 
other questions. However, in order to establish whether the women exhibited a negative or positive attitude, composite score generated from the Likert was used to categorized the attitude as either supportive/negative attitude (higher score) or non-supportive/positive attitude (lower score) using the \pm 1 standard deviation rule. Domestic violence (DV) had three sub categories namely: physical, emotional/verbal and sexual. Each of the categories of DV was dichotomized and coded as 1 if experienced a particular type of violence, otherwise coded as 0. The principal explanatory variable is personality type. Personality type was assessed using brief version of the Big Five Personality Inventory (BVBFPI). It is a short scale version of the well-established BFI developed by Rammstedt and John (2007). It is a 10-item version of the Big Five Inventory in English and German. The five personality type are: Extraversion: 1R, 5; Agreeableness: 2, 7R; Conscientiousness: 3R, 8; Neuroticism: 4F, 9 and Openness to Experience: 5R, 10. Reliability analysis was performed to ascertain the reliability of the scale use. The Cronbach Alpha for the personality scale was $\alpha=0.70$ and attitude towards violence $\alpha=0.77$.

\section{DATA ANALYSIS}

Both descriptive and inferential analysis was performed. The descriptive analysis includes frequency counts, percentages. At the multivariate level, Hierarchical Multiple Regression analysis was performed. All analysis was performed using SPSS Version 22 software.

\section{RESULTS}

\section{Socio-demographic Characteristics of Respondents}

Table 1 presents the distribution of study participants according to socio-demographic characteristics. Respondents in the age group 25-29 accounted for the highest proportion (29.0\%), followed by age group 35-39 years (19.2\%) and 3034 years $(19.0 \%)$. More than two thirds of the women were affiliated to the religion of Christianity (72\%), followed by Islam (23\%), while the traditionalist accounted for the remaining $(5 \%)$. Higher proportion $(55.2 \%)$ of the women had tertiary education, followed by women with secondary education $(35.2 \%)$. The employment status of the respondents showed significant proportions $(80.8 \%)$ of the women were employed. However, respondents earning below $\$ 50,000$ monthly accounted for more than two-third (70.0\%) of the total women surveyed. Also, majority $(80.2 \%)$ of the women were from the monogamous (nuclear) family type, while the remaining (19.8\%) were from the polygamous (extended) family type.

\section{Multivariate Analysis}

Table 2 presents the result of the hierarchical regression analysis. The result revealed that conscientiousness personality type accounted for $11 \%$ percent of the variance in the attitude of women towards domestic violence $(\beta=0.35$, $\mathrm{t}=7.11, \mathrm{p}=.001)$, agreeableness personality type accounted for another $5 \%$ in attitude towards domestic violence $(\beta=0.23$, $\mathrm{t}=4.53, \mathrm{p}=0.001)$. Neuroticism impacted negatively on attitude towards domestic violence by explaining a further $2 \%$ of its variance. The other two traits, that is, extraversion and openness to experience did not explain any of the variance in attitude towards domestic violence $(\beta=0.02, \mathrm{t}=0.36, \mathrm{p}>0.05$; $\beta=0.07, t=1.21, p>0.05$; respectively). These findings imply that only conscientiousness contributed meaningfully to the variance in attitude towards domestic violence.

\section{DISCUSSION AND CONCLUSION}

This study examined the effect of personality trait on attitude towards domestic violence. Prevalence of all forms of violence against the women was high, ranging from $25 \%$ for sexual violence to $60 \%$ for verbal/emotional violence. This finding was consistent with previous studies [22], [23], [24], [25]. These studies reported higher prevalence of spousal violence, with verbal/emotional violence leading in terms of prevalence rate for most studies. The high prevalence of violence among the women might not be unconnected with their supportive and condoning attitude towards the act. For instance, in this study, nearly half of the women endorse the perpetration of violence against women on grounds such as refusing her partner sex, cheating on her husband (sexually) among others, while most of the women did not support that their partner be prosecuted if found guilty of domestic violence. This is not surprising as most women in Nigeria will do whatever it takes to keep their home, not also ignoring the role of religious and community factors. Similar findings have been reported in Demographic and Health Surveys and other studies [26], [27], [5], [28] where women were found to endorse acts such as wife beating if the woman failed in certain responsibilities including refusing her husband sex among others. According to the most recent 2018 Nigeria Demographic and Health Survey, more than one quarter of the women supported wife beating by her partner under certain circumstances. Overall, in this study, personality trait significantly predicted attitude towards domestic violence. Specifically, three of the personality trait - agreeableness, conscientiousness and neuroticism were significant predictors of attitude towards domestic violence, while extraversion and openness did not predict attitude towards domestic violence among the women. While studies [15], [16], [19], have reported personality trait as a significant predictor of attitude towards domestic violence, a study [29] reported personality trait as an important moderator. Nevertheless, in view of the lack of a general consensus on the effect of personality trait on attitude towards domestic violence, this study makes important contribution to literature as it assessed the individual contribution of the Big Five personality trait on attitude towards domestic violence among women in Southwest Nigeria.

\section{ACKNOWLEDGEMENT}

The authors wish to express her profound gratitude to all the study participants for the cooperation during the survey. 


\section{FUNDING}

The author received no specific funding for this work

\section{REFERENCES}

[1] World Health Organization (2013): Fact Sheet. Intimate Partner and Sexual Violence against Women. No.239. Updated October, 2013.

[2] National Population Commission (NPC) [Nigeria] and ICF. (2019). Nigeria Demographic and Health Survey 2018 Key Indicators Report. Abuja, Nigeria, and Rockville, Maryland, USA: NPC and ICF.

[3] WHO (2015). Summary Report World Health Organization. WHO multicounty study on women's Health and Domestic violence against women: Summary report of initial results on prevalence, health outcomes and women's responses, Geneva, Switzerland.

[4] Myers D.G. (2005): Social Psychology ( $8^{\text {th }}$ ed.) Boston, MA: McGraw-Hill.

[5] Flood, M. \& Pease, B. (2009). Factors Influencing Attitudes to Violence against Women. Trauma, Violence and Abuse; 10(2):125-142.

[6] Wang, L., Xu, J., Zou, H., Zhang, H., \& Qu, Y. (2019). Violence against primary caregivers of people with severe mental illness and their knowledge and attitudes towards violence: A crosssectional study in China. Archives of Psychiatric Nursing, 33(6), 167-176.

[7] Gwen S. (2009): Women's Attitudes towards Domestic Violence by Country.

[8] Ali, T.S, Karamali, N, and Malik, O (2014). Women's Perception and Attitudes towards male dominancy and controlling behaviour. Arts and Social Science Journal; 51: 004

[9] Carlson, B. E \& Worden, A. P (2005). Attitudes and beliefs about domestic violence. Result of public opinion survey. Definition of domestic violence, criminal domestic violence and prevalence. Journal of Interpersonal Violence; 20: 1197-1218.

[10] Simon, A., I. (2016). Domestic Violence: The Nigerian Experience. Asia-Africa Journal of Mission and Ministry Vol. 13, pp. 3-16. http://dx.doi.org/10.21806/aamm.2016.13.01

[11] Lamichhane, P., Puri, M., Tamang, J., \& Dulal, B. (2011). Women's status and violence against young married women in rural Nepal. BMC women's health, 11(1), 19.

[12] Rammstedt, B. \& John, O.P. (2007). Big Five Inventory-10 (BF10). Measuring Personality in one minute or less. Journal of Research in Personality; 41, 203-212.

[13] Joshanloo, M. \& Afshari, S. (2009). Big Five Personality Traits and Self-Esteem as Predictor of Life Satisfaction in Iran Muslim University Students. Journal of Happiness Studies; 12 (1): 105113.

[14] Corr, P.J. and Matthews G. (2009). The Cambridge Handbook of Personality Psychology (1. Published ed.). Cambridge, U.K. Cambridge University Press.
[15] Oguntayo, R., Oyeleke, J. T., John-Oguntayo, O., \& AajayiHutchful, F. A. (2020). Personality Traits, Emotional Intelligence, Socio-contextual Factors and Spousal Violence: The Trajectory of COVID-19 Pandemic Lockdown. International Journal of Behavioral Sciences, 14(2), 101-107.

[16] Motevaliyan, S. M., Yaacob, S. N., Juhari, R., Mansor, M., \& Baratvand, M. (2014). Personality traits and severity of wife abuse among Iranian Women. Asian Social Science, 10(7), 234.

[17] Sharma, L.A. (2011). Personality and intimate partner aggression in Gorakhpur, Uttar Pradesh, India.

[18] Sullivan, M., Senturia, K., Negash, T., Shiu-Thornton, S., \& Giday, B. (2005). "For Us It Is Like Living in the Dark" Ethiopian Women's Experiences With Domestic Violence. Journal of interpersonal violence, 20(8), 922-940.

[19] Bernerth, J. B., Armenakis, A. A., Feild, H. S., Giles, W. F., \& Walker, H. J. (2008). The influence of personality differences between subordinates and supervisors on perceptions of LMX: An empirical investigation. Group \& Organization Management, 33(2), 216-240

[20] Pobutsky, A., Brown, M., Nakao, L., \& Reyes-Salvail, F. (2014). Results from the Hawaii domestic violence fatality review, 20002009. Journal of injury and violence research, 6(2), 79.

[21] Gracia, E., García, F., \& Lila, M. (2014). Male police officers' law enforcement preferences in cases of intimate partner violence versus non-intimate interpersonal violence: Do sexist attitudes and empathy matter?. Criminal Justice and Behaviour, 41, 1195-1213.

[22] Ezechi O.C, Kalu B.K, Ezechi L.O, Nwokoro CA, Ndububa V.I., Okeke G.C. (2004). Prevalence and pattern of domestic violence against pregnant Nigerian women. J Obstet Gynaecol;24:652-6.

[23] Igbokwe C.C., Ukwuma M.C. and Onugwu K.J. (2013): Domestic Violence against Women: Challenges to Health and Innovation. JORIND 11(2): 27-35.

[24] Johnson, H., \& Fraser, J. (2011). Specialized domestic violence courts: Do they make women safer. Community Report: Phase I.

[25] Sinha, A., Mallik, S., Sanyal, D., Dasgupta, S., Pal, D., \& Mukherjee, A. (2012). Domestic violence among ever married women of reproductive age group in a slum area of Kolkata. Indian Journal of Public Health, 56(1), 31.

[26] Aderemi, A.V., \& Adelekan, B. A. (2012). Intimate partner violence among married women in Iwo, South West Nigeria: Implications for primary prevention. Family and intimate partner violence quarterly, 5(1), 37-57.

[27] Salahdeen, H., Yemitan, O. K., \& Alada, A. R. A. (2004). Bioline International Official Site (site up-dated regularly). African J. Biomed Res, 7, 27-29.

[28] Malkin, C. (2013). Why Do People Stay in Abusive Relationships?. The Huffington Post.

[29] Yalch, M.M. (2012). Personality as a Moderator of Domestic Violence and Depressive Symptoms in a Community Sample of Women. Michigan State University. Psychology. 
Table 1: Socio-demographic Characteristics of Respondents

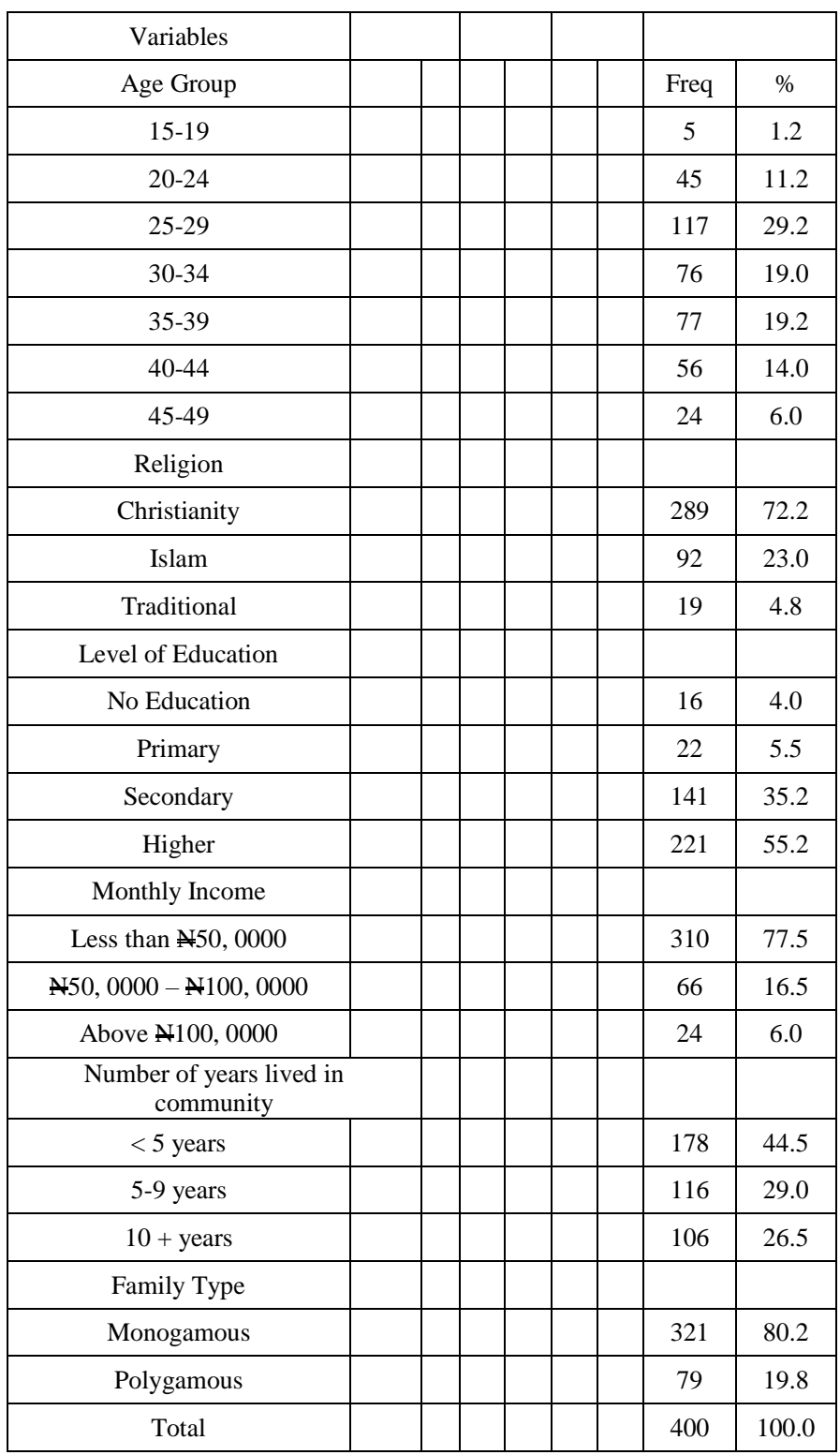

Table 2: Model Summary of the Regression of Attitude towards Domestic Violence on Personality Traits

\begin{tabular}{|c|c|c|c|c|c|c|c|c|c|}
\hline \multicolumn{1}{|c|}{$\begin{array}{c}\text { Mod } \\
\mathrm{el}\end{array}$} & $\mathrm{R}$ & $\mathrm{R}^{2}$ & $\begin{array}{c}\text { Adjust } \\
\text { ed } \mathrm{R}_{2}\end{array}$ & $\begin{array}{c}\text { Std. } \\
\text { Erro } \\
\mathrm{r}\end{array}$ & $\begin{array}{c}\mathrm{R}^{2} \\
\text { chang } \\
\mathrm{e}\end{array}$ & $\begin{array}{c}\mathrm{F} \\
\text { Chang } \\
\mathrm{e}\end{array}$ & $\begin{array}{c}\mathrm{Df} \\
1\end{array}$ & $\begin{array}{c}\mathrm{Df} \\
2\end{array}$ & $\mathrm{p}$ \\
\hline 1 & $\begin{array}{c}0.0 \\
2\end{array}$ & $\begin{array}{c}0.0 \\
0\end{array}$ & -0.00 & 6.55 & 0.00 & 0.13 & 1 & $\begin{array}{c}39 \\
8\end{array}$ & $\begin{array}{c}.72 \\
3\end{array}$ \\
\hline 2 & $\begin{array}{c}0.2 \\
2\end{array}$ & $\begin{array}{c}0.0 \\
5\end{array}$ & 0.00 & 6.39 & 0.05 & 20.51 & 1 & $\begin{array}{c}39 \\
7\end{array}$ & $\begin{array}{c}.00 \\
1\end{array}$ \\
\hline 3 & $\begin{array}{c}0.3 \\
9\end{array}$ & $\begin{array}{c}0.1 \\
6\end{array}$ & 0.16 & 6.03 & 0.11 & 50.53 & 1 & $\begin{array}{c}39 \\
6\end{array}$ & $\begin{array}{c}.00 \\
1\end{array}$ \\
\hline 4 & $\begin{array}{c}0.4 \\
2\end{array}$ & $\begin{array}{c}0.1 \\
8\end{array}$ & 0.18 & 5.97 & 0.02 & 8.45 & 1 & $\begin{array}{c}39 \\
5\end{array}$ & $\begin{array}{c}.00 \\
4\end{array}$ \\
\hline 5 & $\begin{array}{c}0.4 \\
2\end{array}$ & $\begin{array}{c}0.1 \\
8\end{array}$ & 0.17 & 5.97 & 0.00 & 1.47 & 1 & $\begin{array}{c}39 \\
4\end{array}$ & $\begin{array}{c}.22 \\
7\end{array}$ \\
\hline
\end{tabular}

1. Predictors (constant) Extraversion

2. Predictors (constant) Extraversion, Agreeableness

3. Predictors (constant) Extraversion, Agreeableness, Conscientiousness

4. Predictors (constant) Extraversion, Agreeableness, Conscientiousness, Neuroticism

5. Predictors (constant) Extraversion, Agreeableness, Conscientiousness, Neuroticism, Openness

Table 3: Coefficients of the Model Summary of the Regression of Attitude towards Domestic Violence on Personality Traits

\begin{tabular}{|c|c|c|c|c|c|}
\hline & \multicolumn{2}{|c|}{$\begin{array}{c}\text { Unstandardized } \\
\text { coefficients }\end{array}$} & \multicolumn{2}{c|}{$\begin{array}{c}\text { Standardized } \\
\text { coefficients }\end{array}$} & \\
\hline Model & $\mathrm{B}$ & $\begin{array}{c}\text { Std. } \\
\text { Error }\end{array}$ & Beta & $\mathrm{t}$ & $\mathrm{P}$ \\
\hline Extraversion & -0.09 & 0.26 & -0.02 & -0.36 & .723 \\
\hline Agreeableness & 1.26 & 0.28 & 0.23 & 4.53 & .001 \\
\hline Consciousness & 1.58 & 0.22 & 0.35 & 7.11 & .001 \\
\hline Neuroticism & -0.84 & 0.29 & -0.17 & -2.91 & .004 \\
\hline Openness & 0.37 & 0.30 & 0.07 & 1.21 & .227 \\
\hline
\end{tabular}

